\title{
The application of a Business Intelligence tool for strategic planning in a higher education institution: a case study of the University of the Witwatersrand
}

\author{
VINCENT NYALUNGU
}

\begin{abstract}
This article presents a discussion on the importance of business intelligence (BI) and the role that a specific BI tool, Business Intelligence Enterprise Edition, plays in the strategic decision-making processes in an organisation. The University of the Witwatersrand, often referred to as Wits, was used as a case study. The main objective of a business intelligence tool is to improve the quality and timeliness of the input of data to the organisational decision-making process. The quality of the data, which is an organisational asset, is therefore of the utmost importance. Approaches for the identification of business intelligence from corporate information and knowledge management were also assessed. A questionnaire was administered among key informants within the university in order to address some of the pertinent issues at higher education institutions. In addition, the role of a data warehouse within the business intelligence framework was presented. The paper itself covers a wide range of disciplines from information technology, knowledge management to decision sciences. The article also presents a proposed framework to be used in line with the best practices in the implementation of business intelligence solutions.
\end{abstract}

Keywords: Business Intelligence (BI), Business Intelligence Enterprise Edition (BIEE), Data Warehouse, Strategic Decision Making, Strategic Planning, Higher Education Institutions and Knowledge Management.

Disciplines: Information Technology, Knowledge Management, Management Sciences, Decision Sciences \& Management

\section{Introduction}

The rise of the knowledge economy has created new challenges for senior managements and has made managing intellectual capital an integral part of the organisation strategy. This has created a critical need for the development, creation and capturing of value from knowledge and competencies (Augier and Knudsen, 2004:6). For knowledge workers to make informed decisions there is a need for a coherent system, which represents a single version of the truth about organisational performance. Digital networks, such as student and staff databases, provide access to vast amounts of data and

1. School of Information Technology, University of Pretoria.

TD The Journal for Transdisciplinary Research in Southern Africa, 7(1) July 2011, pp. 53-72. 
information, but business intelligence systems are required to translate data and information in a meaningful way. In this study, the researcher looked at the use of one of the decision support tools, namely a business intelligence tool. The BI tool is a tool used to support strategic decision-making processes by making sure that quality information is made readily available. Moreover, the study sought to establish whether the tool implemented at the University of the Witwatersrand had yielded positive results in terms of ensuring that the efficiency in accessing information had improved.

\subsection{Background to the study and aims}

In the rapidly changing higher education environment, it is of the utmost importance for an institution, such as the University of the Witwatersrand, to take into account new information and the latest information patterns that are constantly taking effect. Consequently, if such an institution is to strive economically, information patterns and trends should be interpreted correctly and in a timely fashion to align with current trends in order to facilitate sound strategic decision making. It is therefore imperative for the University of the Witwatersrand, especially the senior management, to have continuous access to information that is crucial for management decision making and strategic planning. A greater emphasis needs to be placed on the conversion of data to business intelligence. This is very important because data alone does not provide insight into an organisation's performance. Only after adding value to this data is its meaning realised, especially when technologies, like business intelligence, are applied to the data. This can be achieved by prioritising issues such as coherent analyses, uniform data definitions, standard interpretations of the information and the availability of up-to-date information for all departments (Guan, Nunez and Welsh, 2002: 168-174).

This article also presents a discussion on the adoption of business intelligence (BI) and attempts to show how important it is as a tool in enhancing the management of information that is needed in strategic decision-making processes at the University of the Witwatersrand. In order to achieve such strategic decision-making goals, an extensive analysis of the entire university was recommended and information priorities as well as associated timeframes for various departments need to be determined. Therefore, the ability to present this complex issue in a reality-based and coherent manner makes it more simplistic and facilitates the identification of important core areas. Because of this, data modelling is strongly aligned with business intelligence and is used to monitor the potential effect and intensity of external factors, which may affect the institution. This involves benchmarking against external factors, such as the competition. Modelling can also be intertwined with environmental scanning, which is one of the most widely preferred methods in strategic management practises (Doomun and Jungum, 2008: 236-237).

According to the researcher, central to most organisation's profitability is the identification and exploitation of new business opportunities and challenges. In today's hypercompetitive business environments, organisations that do not continuously develop and exploit new business opportunities will quickly see their profit margins and long-term growth drop. In contrast, competitors who make use of new opportunities will flourish. Similarly, organisations that fail to effectively manage their new business efforts will see their stock price decline or plunge.

This challenge is particularly crucial for knowledge-based organisations, like the University of the Witwatersrand, as an increasingly rapid technological change has become a primary source of excessive competition. The most recent technological advancement in the higher education sectors are technologies like WebCT (Web Course Tools) and Student Online registrations. These online technologies enable students to interact with institutions without actually having to visit their respective campuses. Students can register, pay for their fees, view and update personal information, access study materials and get their results with the aid of these technologies.

The article's main aim and objectives are as follows: 
- What value did the Business Intelligence Enterprise Edition (BIEE) add to the decisionmaking processes at the University of the Witwatersrand in terms of efficiency improvement?

- What are business intelligence tools and the benefits for organisations?

- What are the challenges encountered when a business intelligence tool is implemented?

- If any, what lessons can be learnt?

\subsection{Business Intelligence, knowledge management and strategic planning}

In today's digital age, companies have large amounts of data in their multiple databases, which often leads to confusion and the mismanagement of data resources. In some cases, there is little correlation between "the practice of capturing large amounts of data and the ability to access the used data to generate actionable information" (Hauser, 2007:45). This normally happens when different systems are used and the data stored in these systems might be of a different format and trying to access this data.

Barnes (2002:17) defines "knowledge management as an integrated, systematic approach to identifying, managing and sharing all of an organisation's intangible assets including: databases, documents, policies, and procedures as well as previously unarticulated expertise and experiences held by individual workers". According to Bhatt (2000) "knowledge management consists of a set of crossdisciplinary and organisational processes that seek to create ongoing and continuous new knowledge by leveraging the synergy of combined information technologies and the creative and innovative capacity of people", as illustrated in Figure 1 below.

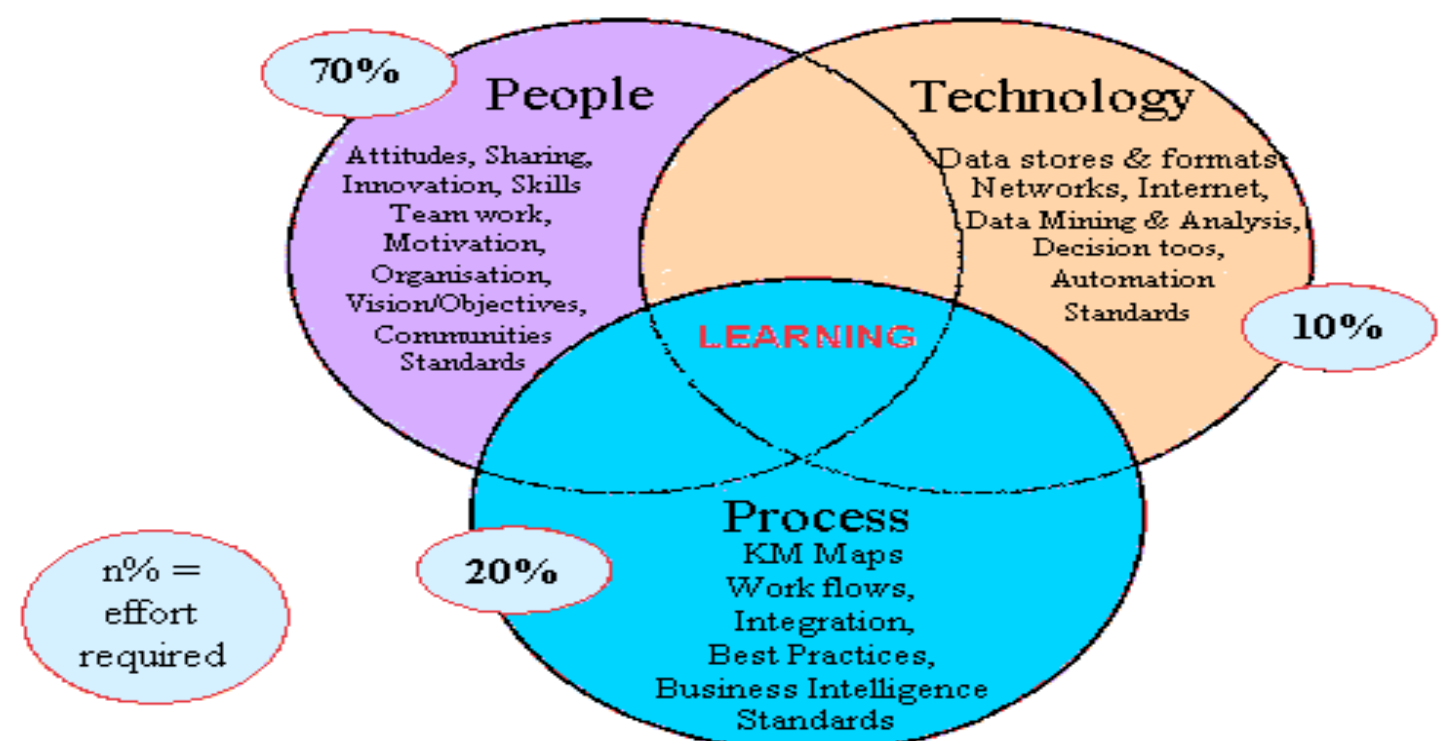

Figure 1: Key components in knowledge management, adopted from Bhatt (2000)

As shown in Figure 1 above, business intelligence together with other analytical tools, such as decision tools and data mining tools, are components of knowledge management. Business intelligence (BI) provide access to vast amounts of data and information and knowledge management is applied to translate information in a meaningful way as managers need to use this information for decision making. At the end of the day, knowledge management is about individuals; it's about people (70\%). 
Clearly, the goal of knowledge management is maintained and sustained by individuals and business performances through on-going learning and unlearning (mainly by getting rid of old ways of doing things). Computing technologies alone have natural limitations. They normally have difficulty in generating important insights from data because they cannot query or re-interpret their programmed logic in the data and the assumptions made by system programmers. Given these limitations, the people who use these 'systems' have at least an equally important role in knowledge management.

Business Intelligence initiatives are unlikely to be successful unless they are integrated with business strategies and related to the development of the core capabilities of the organisation (Snyman and Kruger, 2004:9). In this case study organisation, this strategy is driven by the top management of the University of the Witwatersrand, the Senior Executive Team (SET). This team is in full support of this business intelligence initiative. Executives use this in strategic planning.

According to Hoyt, Huq and Kreiser (2007:1590), responsiveness is one of the most vital characteristics necessary for today's organisations to possess. The ability to know what is happing especially in the external environment can be achieved by deploying a tool like BI to monitor and evaluate the impact that changes are going to have on the business operations. BI tools would most likely be used to do risk and impact analysis. According to Wang and Wang (2008:623), business intelligence can be defined as a broad category of applications and technologies used to gather, access and analyse large sets of data. This kind of information is mainly used in the decision-making processes of any organisation and this is mainly achieved by the use of information technology. In essence, BI involves the integration of core information and relevant contextual information to detect significant events and clarify cloudy issues for management decision makers (Scott and Hill, 2004:49). These management decision makers are mainly involved in strategy development and formulation. BI will form part of the organisation's strategy.

Business intelligence (BI) tools are just some of the most common tools used to assist decision makers in terms of ensuring that sound strategic business decisions are made. These tools are used to alert and advise management once process behaviour deviates significantly from the set Key Performance Indicator (KPI). Some decision makers use research to make intuitive decisions (Sahay and Ranjan, 2008:33-38). The KPIs are normally set by executives and, in general, most BI tools are used to monitor them. An example is where a student registration target has been set and management has to be informed when this target is not reached so as to take corrective action. In most cases things like space and staff allocation will be taken into consideration as they may be affected by the number of students.

The quality of data is one of most crucial elements as wrong decisions can be made from wrong information and data and this will definitely have an adverse effect on any organisation. To address the data quality issues, organisation often use the data warehouse to normalise the data.

\subsection{A Data warehouse}

According to Sugumaran and Bose (1999:71), data is extracted from operational systems, normally an Enterprise Resource Planning (ERP) system and external information sources, then cleansed, aggregated and transformed into a database that is optimised for decision-making. Data warehousing is primarily a concept in the information technology domain and not necessarily associated with a particular technology. However, this is commonly achieved through the use of a relational database management system and a large amount of hard disk space. A relational database management system (RDBMS) is used to access information in a database. 
A typical data warehouse will help with the provision of information that will be used by organisational decision makers. Dobbs, Stone and Abbot (2002:235-236) point out that the amount of data that is currently collected from various sources is increasing rapidly. Therefore, there is a need for businesses to create a tool that will be used to view and disseminate business information; a data warehouse is then used for this purpose.

Organisations, including Wits University, use the data warehousing approach to solve data normalisation problems and to meet business needs. In the case of Wits University, this is used to house student data, including profiles that can then be used for decision making. The data warehouse frees the organisations' information systems from having to constantly program custom reports and queries (Sahay and Ranjan, 2008:42). Users will have to liaise from time to time with the data warehouse team about new data and information requirements and needs.

According to Gargano and Raggad (1999:82), raw data is extracted, loaded and integrated into the warehouse from a variety of external sources. In some cases an extraction, translation and loading (ETL) tool is needed. The University of the Witwatersrand uses the Oracle Warehouse Builder for this purpose. Metadata, which according to Atkinson (2002:21) is data about data, is also an integral part of the system. Simply put, if one uses a picture analogy, metadata can be compared to new digital cameras that provide information about the picture. This information normally appears at the bottom right corner of the picture, which is the picture's metadata, and is normally information about the date when the picture was taken.

In an ideal environment, there must be a data warehouse that is used to store relevant information from the operational or transactional databases and snapshots of these datasets are taken periodically. This is necessary for reporting purposes as decision makers might need certain information aggregated by period, normally monthly or quarterly. Gargano and Raggad (1999:82) describe a data warehouse as a methodology that combines and coordinates many sets of diversified data sets into a unified set of information. Data warehouses will be more flexible and support a wider variety of data types including text, voice, image, spatial and time series data sets.

Accordingly, the data warehouse architecture in most instances must manage standard information delivery systems and data queries. It must also interface with applications such as development platforms and executive information systems (EISs), online analytical processing tools as well as advanced information technology data mining tools. By employing an interactive prototyping methodology and ensuring both scalability and flexibility, the data warehouse will continually evolve and grow rapidly from a small repository of data, information and knowledge to become a very large database (Hurley and Harris, 1997:171-172). Again, not all data from transactional systems is valuable for reporting. Thus data mining techniques are deployed to make sure that only valuable data is mined. Though interlinked data warehousing and data mining are completely different phenomena and the following sections goes a long way in addressing this.

\subsubsection{Data warehousing vs. data mining}

According to Rafalski (2002:609), it is very important to clarify the difference between data warehousing and data mining to make sure that these differences are used consistently as they are sometimes used interchangeably. A data warehouse consists of a set of programs that are used to extract data from the transactional system; it is a term used for the process followed for data collected in a useful form. Through data mining, organisations can use a warehouse to distil the often-valuable information hidden within the data (Rafalski, 2002:609). He also suggests that data mining is a term used to describe the analysis of warehoused data used to generate new insights.

TD, 7(1), July 2011, pp. 53-72. 
Organisations recognise the wealth of information contained in their transactional systems, which is normally the organisations' enterprise resource and planning (ERP) system, like the student systems or the account system in the banking environment. However, the challenge lies in the ways of mining through this information. Since transactional systems were not originally designed to provide realtime analyses and reporting to a larger audience, the system cannot facilitate a decision support function. Therefore, transactional systems would not provide better analytical and reporting functionality.

Data mining is a much more undirected kind of analysis. The process starts with the trends analysis and the search for patterns in the underlying data. Once a pattern of interest is identified, a statistical analysis is applied to determine whether there is a pattern. If this is found to be of significance, the root cause analysis is applied to determine the level of significance. Root cause analysis can be defined as an assortment of techniques, both formal and informal, that may be used to determine these causes (Dorsch, Yasin and Czuchry, 1997:268-269). Analyses in the form of interviews, telephone interviews, focus groups and further data/statistical analyses is done to determine the real causes, problems and issues. Furthermore, Gargano and Raggard (1999:82-83) describes data mining as being concerned with discovering new, meaningful information, so that decision makers can draw and learn as much as they can from their valuable data assets. They also pointed out that data mining is sometimes called data or knowledge discovery and is the process of automating information discovery.

\subsection{Generic business intelligence frameworks}

According to Figure 2 below, the uncovered facts and patterns from data play a critical role in decision making because they reveal areas that need process improvement.

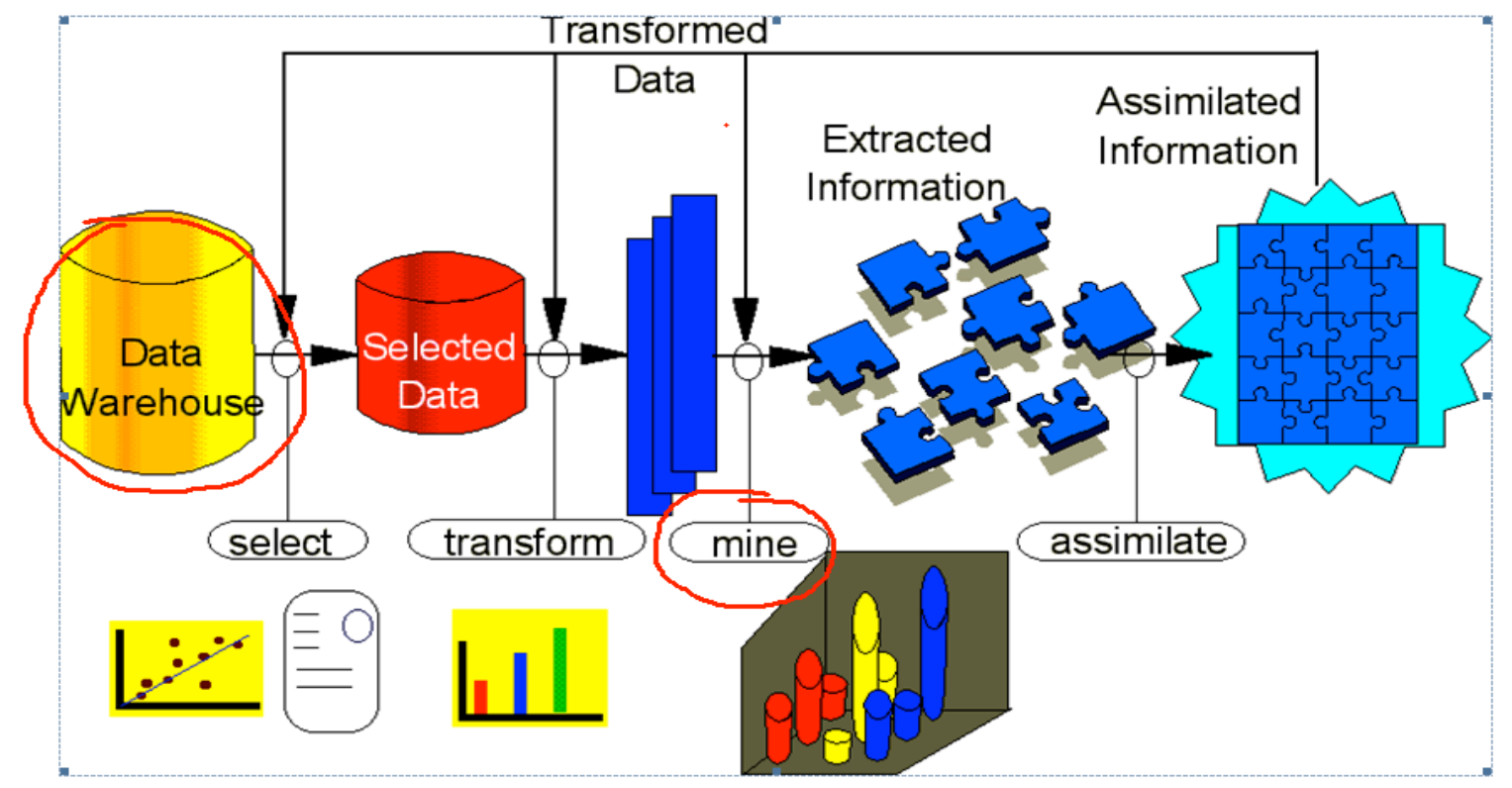

Figure 2: Business intelligence framework, adopted from Simoudis (1995)

Looking at Figure 2 above, one can deduce that a data warehouse and data mining are completely different tools. The data mining tools are used to mine data from various sources including the data warehouse. Most of the value of data mining comes from using data mining technologies to improve predictive modelling and forecasting. For example, data mining can be used to generate predictive models automatically, which predict and build scenarios on how much profit prospects can be made and how much risk will be incurred in the event of fraud, bankruptcy, charge-offs and related 
problems (Gargano and Raggard, 1999: 83). A data warehouse is at the core of most business intelligence frameworks. As adopted from Chou and Tripuramallu (2005), the framework in Figure 3 below provides a generic business intelligence framework.

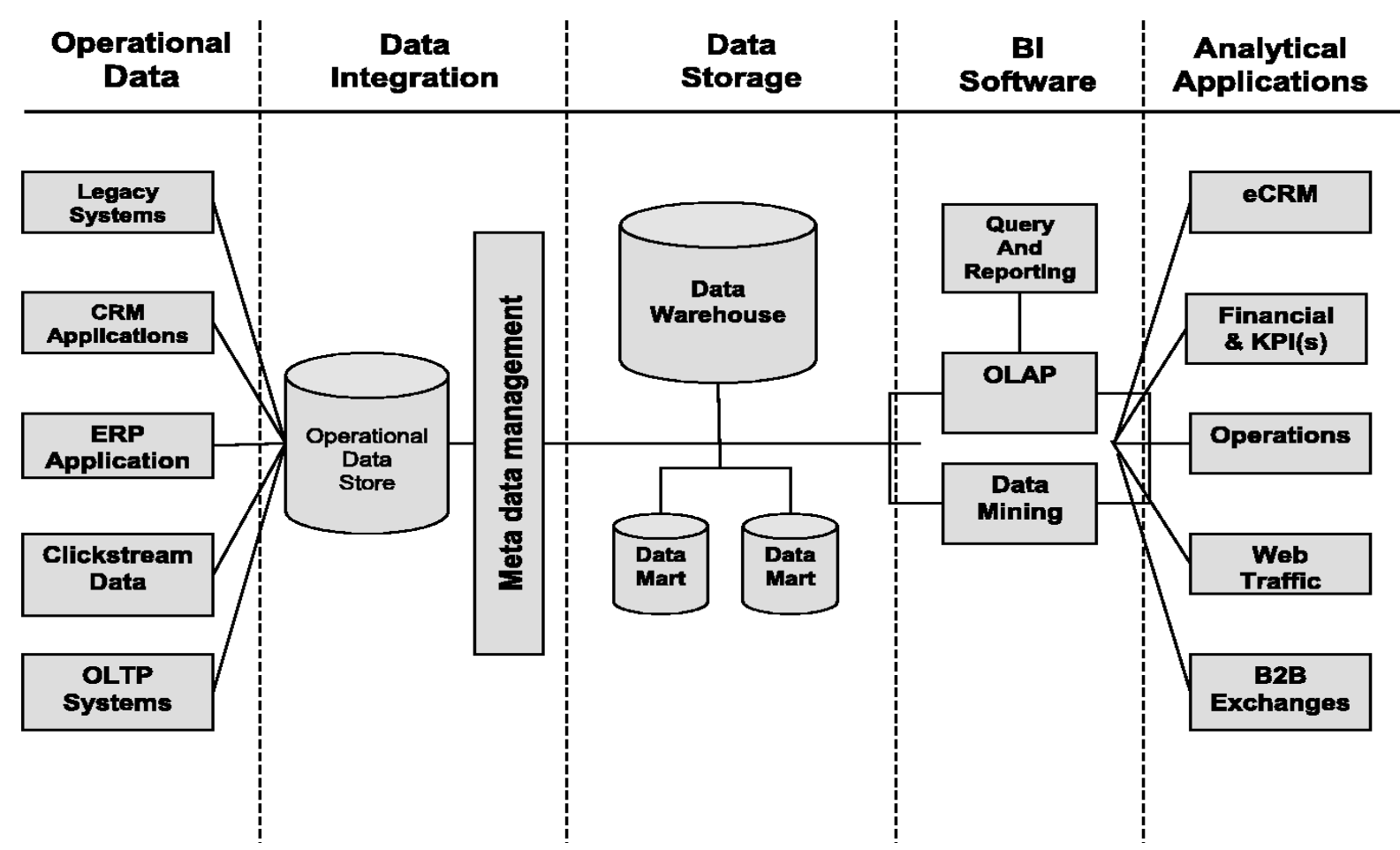

Figure 3: Business intelligence framework (Chou and Tripuramallu, 2005:346)

It is self-evident that data in the business intelligence frameworks provided in Figure 2 and Figure 3 is obtained from various sources mainly transactional systems using extraction, translation and loading (ETL) tools and this is staged in a data warehouse. Thereafter a business intelligence tool is applied to read data from the data warehouse using cubes and queries to present the data from which advanced analytics tools, like the dashboards, are applied to add more value to the information at hand.

The researcher had the opportunity to attend the ItWeb Business Intelligence Summit 2010 hosted by IT Events and Microsoft during February 2010 in Bryanston, South Africa. Organisations seem to be moving to a new BI architecture by using in-memory BI tools. In the past, memory was expensive and processors were slow. Faced with these constraints, developers at the time, devised architecture for delivering results of multi-dimensional analyses, which relied on pre-calculating fixed analyses. Simply put, they pre-calculated all measures across every possible combination of dimensions. The results of these calculations were stored and retrieved when an end user requested a particular analysis. This is what is traditionally referred to as calculating the cube; the cube is the mechanism which organises and stores the results. Because the results were pre-calculated, regardless of how long it took to calculate the results, the response time from the perspective of the end user was instantaneous (ItWeb Business Intelligence Summit 2010, 2010). One of the companies presenting was QlikView. Accordingly, the researcher had the opportunity to interact with the company's representatives and found that, in comparison with other tools that were presented, QlikView seems to be ahead in terms of in-memory business intelligence functionality. Figure 4 below shows a snapshot of the in-memory dashboard functionality by QlikView. 


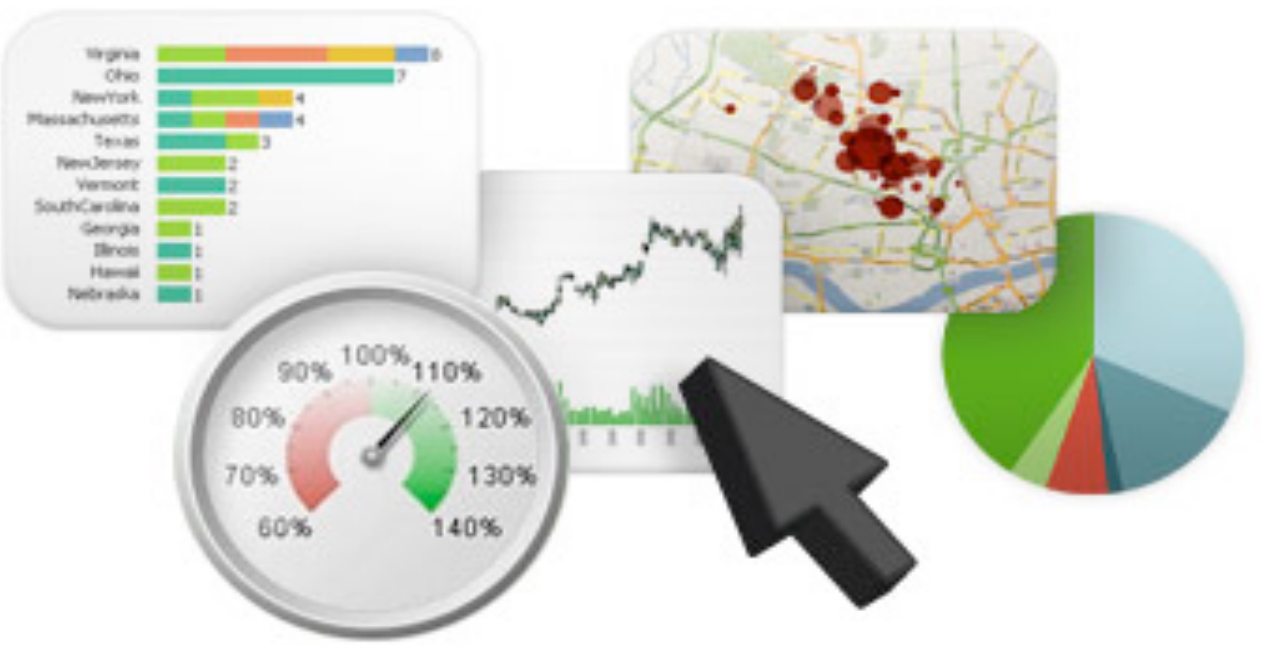

Figure 4: In-memory business intelligence dashboard (QlikView, 2010)

As seen in Figure 4, data is organised in such a way that it can be accessed through one dashboard, which is crucial especially where comparisons are to be drawn. In short, in-Memory BI was built on a simple architectural premise that all data should be held in memory and that all calculations should be performed only when requested. As such, the response rate is very fast.

The aim of organisational performance management (OPM) is to close the gap between strategy and execution. OPM thus reflects the primary goal of the University of the Witwatersrand's integrated planning framework and constitutes an evidence-based performance-oriented management practice. One of the business intelligence frameworks is by Ranjan (2008a). The main advantage when adopting this framework is that an organisation will be able to apply any analytic systems to deal with the issue of response times. This framework is provided below (Figure 5).

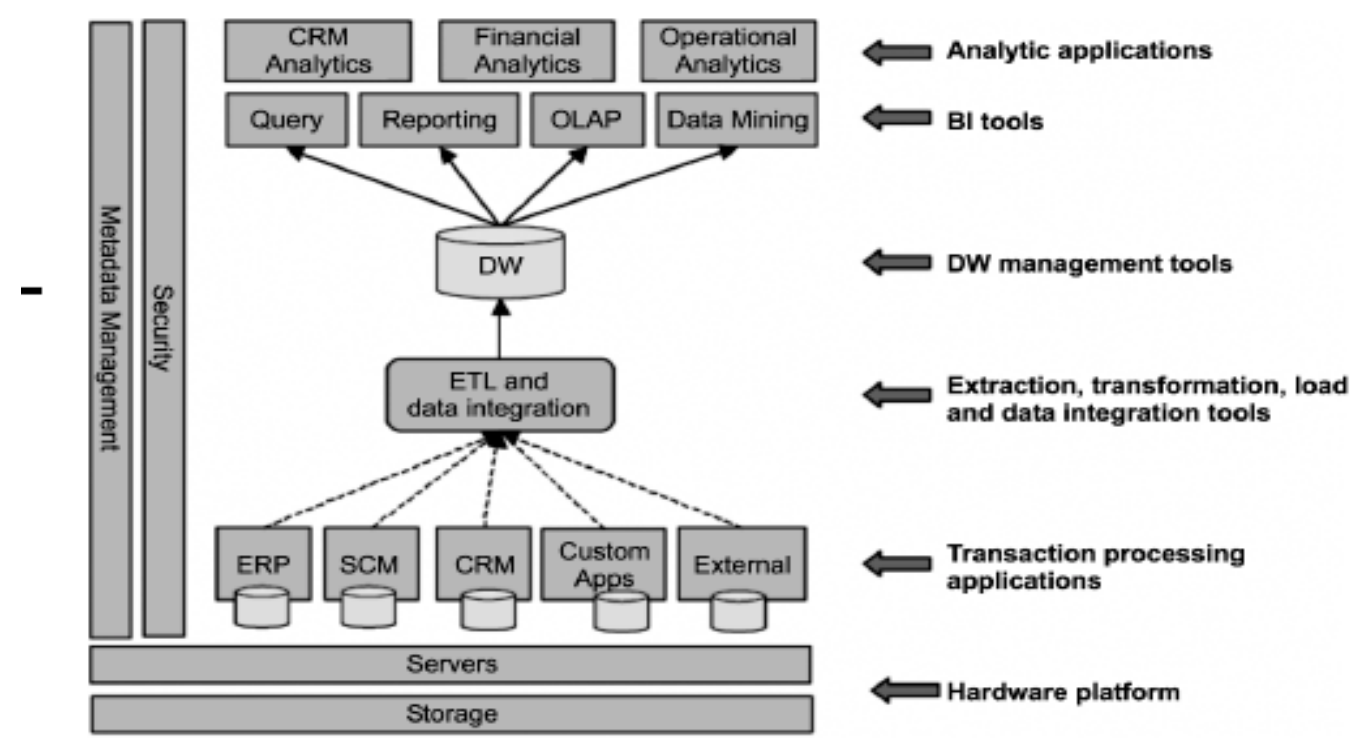

Figure 5: - The BI Framework (Ranjan, 2008a:466)

Looking at the framework in Figure 5 above, one of the features in the framework is the analytics application functionality. According to Bose (2009:155), these advanced analytics have driven data 
analyses to allow organisations to have a complete or 360 degrees view of its operations and customers. The insight gained from such analyses is then used to direct, optimise and automate their decision making.

This BI framework thus systematically provides relevant analytical information across the entire organisation, covering and integrating all processes. Dissemination through the portal allows the analytical information to be customised for each manager in the form of highly graphical dashboards and scorecards, with the ability to drill down into the detailed operational information and not be limited to just providing information to be used on an ad hoc basis. According to Rickards (2003:226227), a scorecard is a performance-oriented type of dashboard. It presents up-to-date actionable BI at a glance on the status of organisational performance against strategic and operational objectives and targets by means of relevant performance indicators. One of the most important components of business intelligence is the dashboard, which is more a front-end tool that provides a single view of the data in a graphical manner.

According to Chou and Tripuramallu (2005:343), BI tools are used to analyse the short-term and long-term business scenarios and cases using existing data captured from the organisational information systems. Business Objects, Cognos and Integrated Data Viewer (IDV) solutions are some of the commercially available BI tools. All these tools have one thing in common: a dashboard interface. IDV Solutions is a software company that specialises in dashboard interfaces for enterprise BI applications (Hedgebeth, 2007:416-417).

The business intelligence tool deployed at the University of the Witwatersrand uses dashboard technology to visualise the data. The production of a dashboard provides feedback on current performances and predefines normal targets. Tapp and Greatbanks (2007: 847-866) define the role of a dashboard as providing a means for managers to monitor, analyse and sometimes annotate data (e.g. explaining variances in an embedded scorecard). They also state that there are several strong relationships to planning and budgeting, such as:

- Displaying, analysing, and comparing historical figures with budgets, forecasts and targets.

- Monitoring of resource allocation figures whereby business units can propose investments of discretionary funds in various programs and projects.

- Focused dashboards for deep analysis of budgets and forecasts for example, can be particularly effective when dashboards are fully integrated with planning tools, and organisations utilise a continuous planning methodology. Managers can then analyse trends and variances in a dashboard, almost immediately revise a forecast and then see it updated back in the dashboard in real time.

- Monitoring and sharing of strategies across business units.

According to Bose (2009: 164-166), most comprehensive business intelligence suites in the market today offer dashboards that are tightly (or lightly) integrated with sophisticated analytical modules that offer various functionality, such as: heat maps, data mining, drill up and down, statistical analyses, predictive analyses and trend analyses. These belong to a family of tools called advanced BI analytical tools. Together with business dashboards these specialised analytical tools further empower decision makers to support performance management initiatives. In some instances, most dashboards do not reflect real time data (that is, they are based on data that on a periodic basis is loaded from transactional databases into a data warehouse and into Online Analytical Processing [OLAP] cubes).

Some of the concepts that various formal strategic planning processes use certainly have value. For instance, the SWOT (Strength, Weaknesses, Opportunities and Threats) Analysis is used to do an analysis on the organisation's strengths, weaknesses, opportunities and threats given the basic goals TD, 7(1), July 2011, pp. 53-72. 
that the organisation wants to attain. Obviously, it would be naïve for any organisation to create a strategy for achieving a goal without taking into account their organisation's strengths and weaknesses as well as the competitive environment (Linn, 2008:22).

\section{Methodology}

The researcher used the mixed methods approach, which is mainly composed of the usage of both qualitative and quantitative research methods and triangulation (De Vos et al., 2005:361). The value of the mixed methods approach lies in its ability to help expand the scope of the research by being able to provide more insight from the study at hand that enriches the research experience (Sandelowski, 2000:246). Moreover, the mixed methods approach possesses an inherent capability of capturing the complexity of human behaviour and reality by using both qualitative and quantitative methods. A wider variety of responses can be elicited than if one were to employ only one method (De Vos et al., 2005:361; Sandelowski, 2000:247). The mixed methods approach in this case suited the research, in that it could capture the various perceptions of users of the tool at the University of the Witwatersrand.

It is chiefly because of the abovementioned advantages of the mixed methods approach that triangulation is used in this research. Triangulation involves using both qualitative and quantitative methods of data collection and data analysis. With regard to data collection, using both qualitative and quantitative methods will assist in unlocking more insights into perceptions of the users of the BI tool. Consecutively, this will help to ensure the validity of the findings of the research, therefore establishing a measure of 'convergent validity', in the study (Sandelowski, 2000:248). In the case of data analyses, the combination of qualitative and quantitative modes of analysis has the added advantage of 'corroborating data' (Sandelowski, 2000:248). This helps to consolidate the research findings more, than would have been the case if a single mode of either qualitative or quantitative data analysis had been used.

\section{Data analysis and discussion}

These findings are composed of the overall perceptions of the users of the Business Intelligence Enterprise Edition (BIEE) tool and analysis of the data as collected from the selected users (managers and supervisors) at the University of the Witwatersrand. The perceptions of the key personnel involved in the implementation of the tool are also addressed.

\subsection{Respondents profiles (background) and findings}

The population for this study was made up of 40 respondents, namely: executives, managers, supervisors and deans at the University of the Witwatersrand. In terms of the responses, a total of 21 respondents answered the survey, which signifies a 53\% response rate for the first questionnaire that was administered. This response rate is considered to be high, even more than the $49 \%$ response rate benchmark set by Rao (2009:165).

These respondents were classified according to certain categories. Figure 6 below illustrates this: 


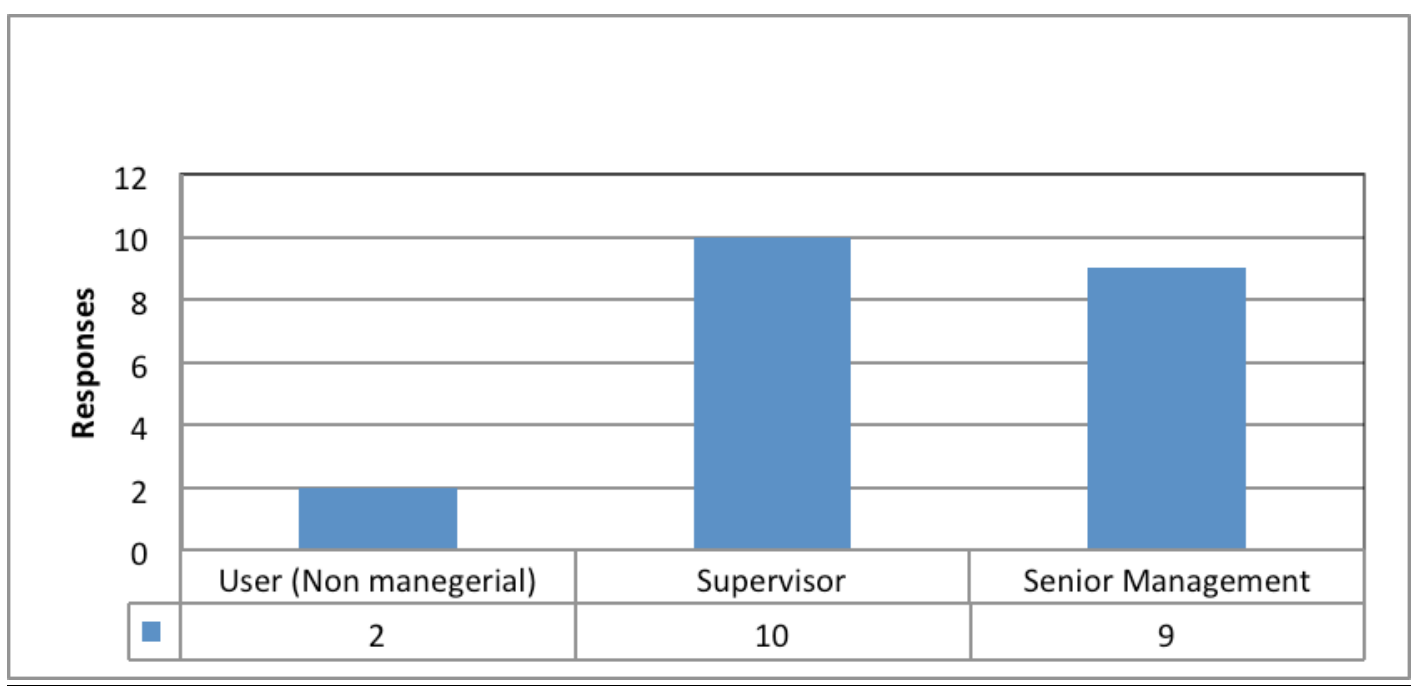

Figure 6: Respondent Profile: Job classification

Figure 6 above shows that the majority of respondents were mostly supervisory or managerial staff (10), followed by the senior management (9) and then the users (2). The senior management category included a high-ranking deputy vice-chancellor of the university and a few deans of faculties and heads of departments. The data reveals that there might not have been any significant differences in the way the three categories reviewed their experience with the BI system. This is especially true in terms of efficiency improvement, where after using the tool they felt that they could perform their function more efficiently than before. This study was aimed at senior executives, managers and other users. This is due to the fact that this particular group was somewhat involved in processes of decision-making or its support and because of the years they spent at the University of the Witwatersrand as employees. The respondents revealed that there was no wide consultation by the University among interested parties in the implementation of the BI tool. A total of 14 out of 21 respondents affirmed that no consultation had been put in place; they only became new consumers when the process had been initiated and could not have a say in it. Figure 7 below shows that there was little consultation during the implementation process, which is one of the main themes in the study. According to Maguire, Ojiako and Said (2009:81), any system that is related to implementation needs a full consultation and transparency commitment with all stakeholders involved.

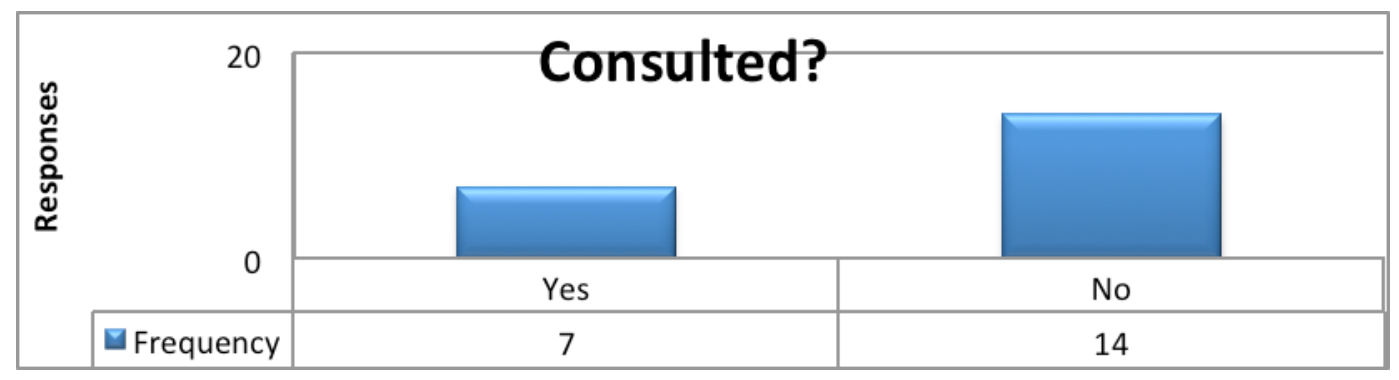

Figure 7: Results for the question: 'Were you consulted during the implementation process?'

The absence of prior consultation could have been arguably 'compensated' for by the fact that the same respondents were trained (see Figure 8 below) before making use of the tool. 


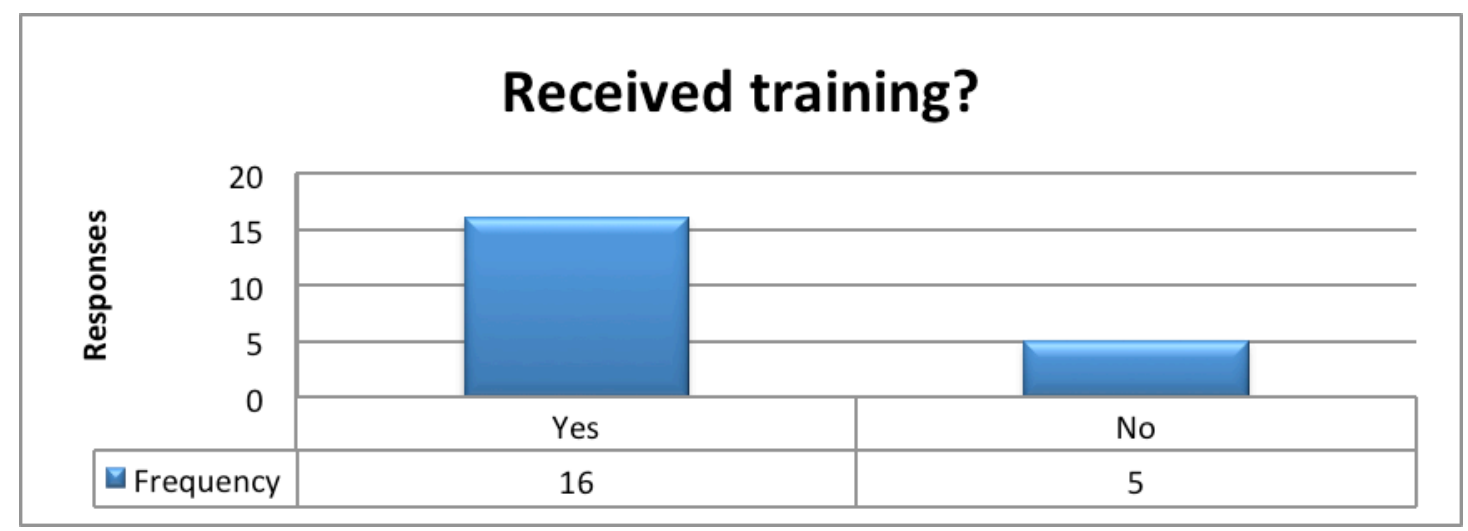

Figure 8: Results for the question: 'Did you receive training before using the tool?'

According to Figure 8 above, 16 respondents or $76.2 \%$ of the respondents received prior training before they used the BIEE tool. This signified the importance of receiving training before one starts using the tool. The provision of best practices on the BIEE tool usage enhances the optimal use of the tool (Ranjan, 2008a:471).

\subsection{The importance of providing quality data}

Once any system has been implemented, the major challenge when it goes live is the quality of data at the users' disposal. Figure 9 below clarifies this fact:

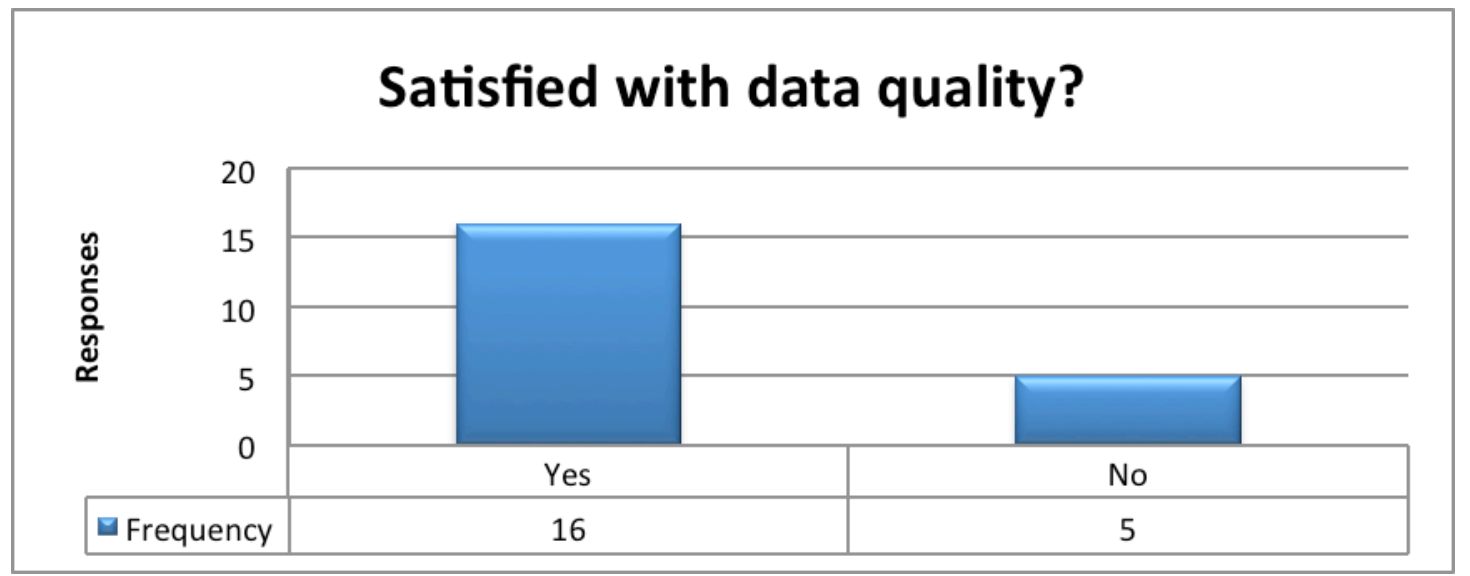

Figure 9: Results for the question: 'Are you satisfied with the quality of data provided by the tool?'

The majority of the respondents expressed high levels of satisfaction with the quality of data provided by the tool (76.2\%) while only $23.8 \%$ said they were not satisfied. This high level of satisfaction shows that the majority of the respondents were able to adapt to the new tool and effectively use it with ease since its implementation. It also implies that the data they had at their disposal was high in quality and distilled from this could execute better decision-making. If the tools provided high quality data, this could be used for decision-making and saves managers' time and effort; it meant that the tool was serving its purpose as discussed by Ranjan (2008b:58-59). 


\subsection{The tool efficiency and usability}

Figure 10 below proved the fact that the tool has overall yielded positive developments for the University of the Witwatersrand.

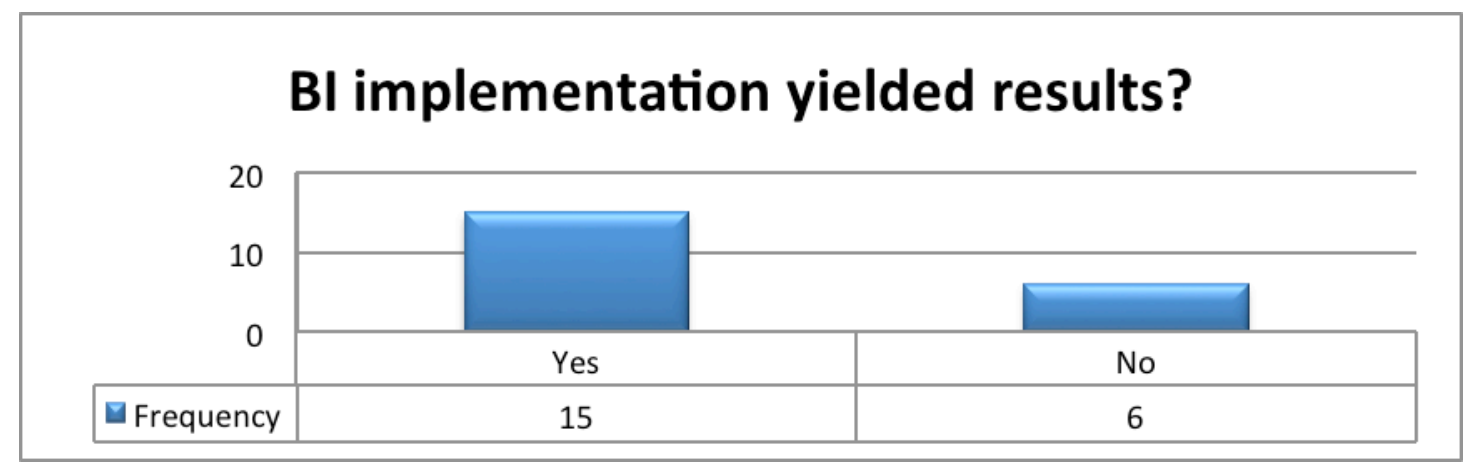

Figure 10: Results for the question: 'Has the BI implementation yielded results?'

Figure 10 above shows that in totality, the implementation of BI at the University of the Witwatersrand had been fruitful, according to 15 of the respondents (71.4\%). For example, one respondent, a head of school said: 'I am able to access data quickly.' Another member of senior management said: 'Managers have real-time information at hand.' These responses show the positive perceptions of the users regarding the system. This real time information is used in strategic decisionmaking processes and thereby supports the university's strategic planning aspirations. A smaller portion of respondents $(28.6 \%)$, did not agree that the BI implementation yielded positive results. One of the respondent's reason was that '[he does not] know how to use the tool'. Again, this clearly shows that training is still one of the important aspects.

\subsection{Perspectives of system implementers}

The study also sought the opinions and perceptions of two respondents with technical expertise and who were involved in the implementation of the system from the start of the process till the implementation stage of the BIEE tool. These people were from the Management Information Unit (MIU) and worked with the Computer and Networks Services (CNS), which provided the required IT infrastructure. At the University of the Witwatersrand, the Management Information Unit is responsible for the official reporting of information to various internal and external stakeholders, including the Department of Higher Education and Training (DoHET). The areas of the research that necessitated the collection of data were based on two vital issues about the system, that is: the challenges faced in operating a new tool and whether there were any recognisable changes in operational efficiency in the organisation. In addition, the research needed to find out whether there had been any lessons learnt in the implementation process.

The two respondents cited three challenges that were faced in implementing the new system. The first two are 'content' (what data was needed for the warehouse) and 'design'. The third is that Tata Consulting Services (one of the top 10 development firms in the world) are not familiar with both the multidimensional design techniques for star schemas and the implementation in parallel with implementing the ERP. 
Both respondents felt that the greatest risk or threat to the implementation of the new system was implementing the BIEE together with ERP. This was due to the fact that, according to the one respondent, "[they] did not have a firm foundation on which to build the system, nor did anyone have all the answers. ERP was being customised as [they] were building the BI infrastructure.' In essence the operational systems did not cater for the elements required to answer some business questions, which led to the team changing the operation system to meet the BI needs. According to Bose (2009:178-184), BI includes adding value to the data drawn from the operational systems by applying advanced analytics. This is a general term that simply means applying various advanced analytic techniques to data to answer questions or solve problems and support strategic planning and decision making.

With regard to operational efficiency, the respondents felt that the new system had indeed improved. Before the new system had been implemented, operating different database management systems were quite complex due to their differing principles, rules and operations. Again Bose (2009:157-171) describes business rules as consistently applying logical conditions to determine how a certain case should be handled. This is one of the main challenges in the management information domain. Users interpreted data differently as they had to apply context to the raw data before they could produce any value from the data provided. These business rules were documented to make sure that there was standardisation in the business terminology used, for example a headcount would mean the unduplicated number of students registered in the institution irrespective of the number of the qualifications they registered for. One respondent pointed out that '[d]ifferent business rules were used to populate and extract data from the various management information databases and these databases were populated according with different regularities and routine. However, with the new data warehouse, [they] are using a single set of technologies, business rules, design principles, ETL schedules etc. which brings [them] closer to [a] single version of the truth.'

The introduction of BIEE changed things dramatically, according to another respondent who said that: "Prior to the enterprise data warehouse, we had the common problem of "Islands of BI" or data mart type structures that had been designed and built by different areas (CNS and MIU), using different technologies (MSSQL, Adabas, PCs, mainframes), which were structured according to different principles (the student 'data mart' was on the mainframe and implemented using entity relational design schemas, whereas we also had student data marts in Essbase using multidimensional schemas using OLAP in Essbase)'

The implementers of the systems realised that as time went by, a multi-tier warehouse was the best approach. It provided a single source of clean, integrated data, as well as local stores tailored to the needs of specific groups within the university community. A data warehouse was therefore an orderly and accessible repository of known facts and related data that was used as a basis for making better management decisions. In a data warehouse, data must be identified, catalogued and stored using structures that enable users to find the correct information when they need it.

A number of valuable lessons had been learnt in implementing the new BI system, according to the two respondents: 'The Management Information team grew as a result of being exposed to the methodologies and disciplines used by Tata Consulting Services (TCS).'

Apart from achieving growth in human resource capacity the MIU team realised the need to stop outsourcing their future core applications among others. Accordingly according one of the key implementers, "The outsourcing of transactional systems was often problematic as organisations would always rely on vendors for support. Vendors often withheld system specific information on purpose so that they should always be called in when there are problems with the systems and then charge exorbitant fees to fix bugs in their systems'. 
The respondents also learnt that it was ideal not to run parallel systems: 'Although inevitable, developing a BI application in parallel with an ERP implementation should be avoided because of ... risk[s].' According to Bose (2009), this might affect system response time as the processors will be overloaded.

Lastly, another lesson that was learnt was stated in this respondent's opinion: 'A final, very important lesson we learnt, was that ERP sales vendors make out that ERP solutions will meet reporting requirements due to the large number of standard reports that they have in the university setting, the vast majority of reports could not be used as they do not meet requirements, they were expensive to modify, and it turned out that it was imperative to build a data warehouse solution to complement the ERP to produce operational, management and strategic reporting functionality.'

According to Sahay and Ranjan (2008:34), it is also important to note that the lessons learnt show that the 'one size fits all' approach advocated and endorsed by vendors is a serious problem. Organisations are different and have different needs hence the solutions provided must be customised to meet that specific need.

\section{Summary of the findings}

The totality of the research findings is based on the variety of perceptions and views from the users of the system, namely: supervisors, managers and senior managers. It is also based on the views expressed by the implementers of the system, as is shown below:

- The users' opinions concerning BIEE or the dashboard were that it had overall improved efficiency and access to information to be used in support of the decision-making processes.

- The implementers also felt that the new system provided a better level of operational efficiency despite a number of challenges faced in implementing it, on top of the various lessons that were learnt in terms of improving the methodology adopted when the data warehouse was designed.

\subsection{The implementation of the BI tool}

As discussed in this study, it became evident from the study that the users' opinions concerning the dashboard or tool were that overall it has improved efficiency and access to information that is used in support of the decision-making processes. These findings were analysed from the data collected through the email questionnaire. Again, as some themes suggest the following also plays a role in terms of making sure the implementation of this tool is a success:

- The importance of training;

- Consultation;

- Ease of use; and

- The quality of data. 


\subsection{The implementers' findings}

The system implementers felt that the new system provided a better level of operational efficiency despite a number of challenges faced in implementing it. There were also various lessons that were learnt in terms of improving the methodology adopted when the data warehouse was designed and developed. Again the parallel implementation of the BI tool and the students' system did not do any justice to the implementation process.

Overall, the research findings show that there was a great deal of improvement in the way decision makers access their information with greater emphasis on efficiency improvement. Managers, supervisors and general users have information at their fingertips to support their decision making, which means they can make timely decisions.

\subsection{Consultation and buy-in}

Over and above the aforementioned the following section looks at other recommendations: Firstly, it is important to begin the business intelligence implementation process with a clear understanding of the operational development access to this data will provide. Simply by knowing how the data will be utilised, the problems it can help solve and the decision-making it can support, it is possible to develop a return on investment (ROI) calculation that allows organisations' top-executives to estimate the benefits of the system. The importance of management buy-in cannot be overemphasised, according to Hedgebeth (2007:414). A typical BI implementation effort touches almost every aspect of an organisation. If an organisation determines that creating such a system is cost-effective, the BI implementation process must begin with developing a support system at the highest levels of the organisation's executive management.

Secondly, business intelligence systems are often developed and implemented with outside consultants. Seeing as there was little involvement by staff members within the University of the Witwatersrand, it is recommended that employees be trained in how the system works, the benefits it provides and the use of its tools in order to enhance the prospects of success for implementing the system. The trained staff will also help train other staff members and make sure that the new tool is fully operational.

\section{Recommendations and a proposed business intelligence framework}

In the wake of the new developments in the business intelligence environment, the University of the Witwatersrand should also consider new frameworks seeing that users will normally complain about systems response times, especially when historical information about a student is retrieved.

\section{1 Proposed business intelligence framework}

In principle the tool is not an issue, rather the framework under which it was implemented is the issue. More often than not a student's historical records cannot be deleted and for older universities this is a serious challenge as students will request this information and data from time to time. That's why a BI framework in Figure 5.1 is proposed, especially for a higher education institution to make sure that there is a coherent structure followed when implementing a BI tool. The framework by Ranjan (2008a:246) as illustrated in Figure 11 provides a best fit for an organisation like the University of the Witwatersrand. 
Web Analytics, Students Portal, Finance and HR Dashboard

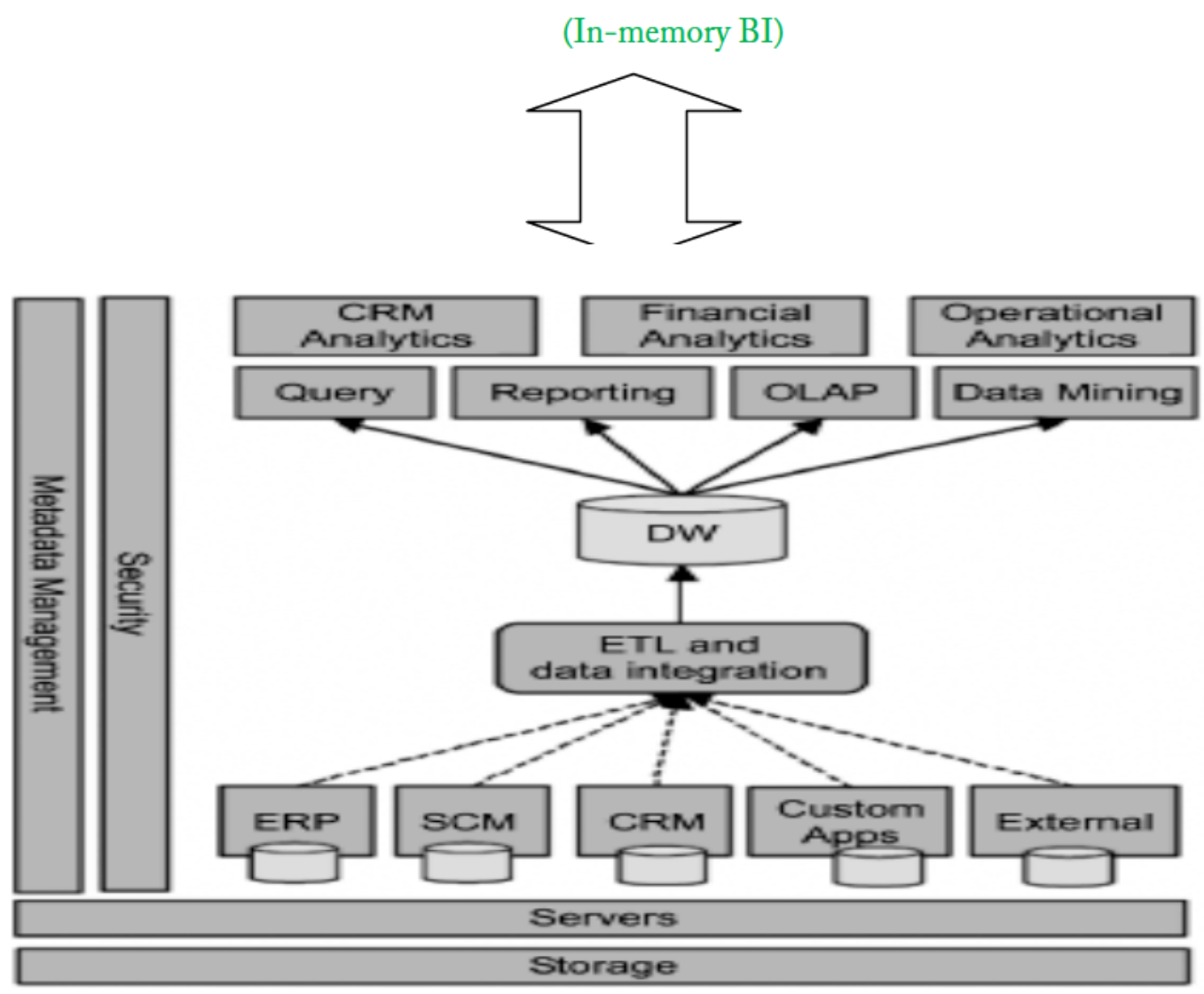

Figure 11: The BI Framework, adopted from Ranjan (2008a:466)

In order to provide some concrete indications of how the BI framework might be implemented or reviewed at University of the Witwatersrand, the following BI domains have been identified:

- Students: biographical information and academic information;

- Programmes and courses: information relating to the academic structure, enrolments, success and throughput rates;

- Human resources: biographical information, information relating to conditions of service (remuneration and benefits), workload, research outputs, etc; and

- Finance: income and expenditure, assets and liabilities, procurement, estates etc.

In the proposed framework (Figure 11) for the University of the Witwatersrand, the student web portal is integrated with the human resources (HR) and financial components and this will be visible through a fully functional dashboard. The reason for this is that there should be consistency in the reporting framework at the university as there are always relationships in the mentioned systems, the student system, HR and finance. A student's account information is always housed in different systems just like the student and HR systems. The link between student and HR systems is normally information about lecturers and information about students in their respective classes. Thus decision makers will have information at their fingertips to make decisions in support of the strategic priorities of the organisation thus contributing to the strategic planning of the organisation.

TD, 7(1), July 2011, pp. 53-72. 


\section{Conclusion}

According to the findings of the study, it is apparent that the business intelligence tool implemented at the University of the Witwatersrand has yielded positive developments in making sure that efficiency is improved and users at different levels have access to information that they can use in support of decision-making processes. Though this was not a smooth an easy feat in terms of the challenges encountered when the tool was implemented and users feel that there is still a lot to be done to make it complete. The lessons learnt during implementation will be used when enhancements are done to the current system.

\section{References}

Atkinson, E. (2002). Much ado about metadata. Records Management Journal, 12(1):19-23.

Augier, M. \& Knudsen, T. (2004). The architecture and design of the knowledge organization. Journal of Knowledge Management, 8(4):6-20.

Barnes, S. (2002). Knowledge management systems, theory and practice. London: Thompson Learning, Cengage Learning Business Press.

Bhatt, D. (2000). EFQM Excellence Model and Knowledge Management Implications. [Online] Available from: http://www.eknowledgecenter.com/articles/1010/1010.htm (Accessed: 1 May 2010).

Bose, R. (2006). Understanding management data systems for enterprise performance management. Industrial Management \& Data System Journal, 106(1):43-59.

Bose, R. (2009). Advanced analytics: opportunities and challenges. Industrial Management E Data System journal, 109(2):155-172.

Chou, D. \& Tripuramallu, B. (2005). BI and ERP Integration. Information Management E Computer Security, 13(5):340-349.

De Vos, A.S., Strydom, H., Fouche, C.B. \& Delport, C.S.L. (2005). Research at grassroots. $3^{\text {rd }}$ Edition. Pretoria: Van Schaik.

Dobbs, T.; Stone, M. \& Abbot, J. (2002). UK data warehousing and business intelligence implementation. Qualitative Market Research, 5(4):235-238.

Doomun, R. \& Jungum, N.V. (2008). Business process modelling, simulation and reengineering: call centres. Business Process Management, 5(4):235-238.

Dorsch, J.; Yasin, M. \& Czuchry, A. (1997). Application of root cause analysis in a service delivery operational environment. International Journal of Service Industry Management, 8(4):268-289.

Gargano, M.L. \& Raggad, B.G. (1999). Data mining- a powerful information creating tool. OCLC Systems Services, 15(2): 81-90. 
Guan, J., Nunez, W. \& Welsh, J. (2002). Institutional strategy and information support: the role of data warehousing in higher education. Campus-Wide Information Systems Journal, 101(4):168174 .

Hauser, W.J. (2007). Marketing analytics: the evolution of marketing research in the twenty-first. Direct Marketing: An International Journal, 1(1):38-54.

Hedgebeth, D. (2007). Data-driven decision making for the enterprise: an overview of business intelligence applications. VINE, 37(4): 414-420.

Hoyt, J.; Huq, F. \& Kreiser, P. (2007). Measuring organisational responsiveness: the development of a validated survey instrument. Management Decision Journal, 45(10):1573-1747.

Hurley, M.A. \& Harris, R. (1997). Facilitating corporate knowledge: building the data warehouse. Information Management \& Computer Security Journal, 5(5):170-174.

In-memory Business intelligence dashboard, [Online] Available from: http://www.qlikview.com (Accessed: 30 July 2010)

ItWeb Business Intelligence Summit 2010. (2010). [Online] Available from: http://ww2.itweb.co.za/events/bi2010 (Accessed: 30 June 2010).

Linn, M. (2008). Library strategies: Planning strategically and strategic planning. The Bottom Line: Managing Library Finances, 21(1):20-23.

Maguire, S.; Ojiako, U. \& Said, A. (2009). ERP implementation in Omantel: a case study. Industrial Management E Data Systems, 110(1):78-92.

QlikView. (2010). In-memory Business intelligence dashboard, [Online] Available from: http://www.qlikview.com (Accessed: 30 July 2010)

Rafalski, E. (2002). Using data mining/data repository methods to identify marketing opportunities in health care. Journal of Consumer Marketing, 19(7):607-613.

Ranjan, J. (2008a). Business justification with business intelligence. Journal of Information and Management Systems, 38(4):461-475.

Ranjan, J. (2008b). Hurdles and Opportunities for Indian firms adopting Business Intelligence. Journal of Advanced Management Research, 5(1):56-62.

Rao, P. (2009). International survey research: Understanding national cultures to increase survey response rate. Cross Cultural Management: An International Journal, 16(2):165-178.

Rickards, R. (2003). Setting benchmarks and evaluating balanced scorecards with data envelopment analysis. Benchmarking: An International Journal, 10(3):226-245.

Sahay, B.S. \& Ranjan, J. (2008). Real time business intelligence in supply chain analytics. Information Management \& Computer Security Journal, 16(1):28-48. 
Sandelowski, M. (2000). Combining qualitative and quantitative sampling, data collection, and analysis techniques in mixed-method Studies. Research in Nursing \& Health, 23(1): 246-255.

Scott, T. \& Hill, J. (2004). A consideration of the roles of business intelligence in e-business in management and marketing decision making in knowledge-based and high-tech start-ups. Qualitative Market Research: An International Journal, 7(1):48-57.

Simoudis, E. (1995). Reality check for data mining, IBM Almaden Research Centre. [Online] Available from: http://www.almaden.ibm.com/stss/papers/reality/ (Accessed: 01 May 2010).

Snyman, R. \& Kruger, J. (2004). The interdependency between strategic management and strategic knowledge management. Journal of Knowledge Management, 8(1):5-19.

Sugumaran, V. \& Bose, R. (1999). Data analysis and mining environment: a distributed intelligent agent technology application. Industrial Management Data System journal, 99(2):71-80.

Tapp, D. \& Greatbanks, R. (2007). The impact of balanced scorecards in a public sector environment: Empirical evidence from Dunedin City Council, New Zealand. International Journal of Operations \& Production Management, 27(8):846-873.

Wang, H. \& Wang, S. (2008). A knowledge management approach to data mining process for business intelligence. Industrial Management Data System Journal, 108 (5):622-634. 